\title{
In memoriam: Hans Gerd Schiefer (1935-2014)
}

\section{A. von Graevenitz}

Published online: 18 November 2014

(C) Springer-Verlag Berlin Heidelberg 2014

Professor Hans Gerd Schiefer, known to many of us as a medical microbiologist with a strong interest in infectious diseases, died on October 11, 2014 from complications of a malignant tumor. Born on December 17, 1935 in Wuppertal-Elberfeld, he studied medicine at the universities of Marburg, Munich, and Düsseldorf and interrupted his studies for a 2-year period of work in the biochemistry laboratory of the Federal Institute of Technology in Zurich under the direction of Carl Martius. After receiving his M.D. degree in 1962, he interned in medicine in Duisburg, Essen, and Cologne and again in biochemistry at the University of Cologne and at the Max Planck Institute for Experimental medicine in Göttingen. In 1971, he became a fellow at the Institute of Medical Microbiology of the University of Giessen, qualified in 1972 as a specialist in Laboratory Medicine, and became Assistant Professor for Medical Microbiology and Urogenital and Sexually Transmitted Diseases in 1974. In 1975, he was named Professor at that institution.

He used his knowledge in biochemistry to study the surface structure and chemistry of the membranes of mycoplasmas, ureaplasmas, and chlamydiae and, at the same time, the function of these organisms in clinical microbiology. In cooperation with the urology group at Giessen, he engaged in research on pathology, diagnosis, and therapy of urethritis, prostatitis/prostatosis, and epididymitis. From
1971 until his retirement in 2001, he also directed the diagnostic laboratories of the Institute of Medical Microbiology, provided clinicians with advice in microbiology and infectious disease, and lectured to students in microbiology and infectious diseases.

He was a prolific writer (220 publications, 3 of them in Infection), a thorough reviewer for several journals, and an acribic clinical microbiologist. From his early studies on rickettsiae and coxiellae, he had also maintained an active interest in zoonoses. He co-authored the Zoonosen volume (Deutscher Aerzte-Verlag; first edition, 1986) which became so successful that a fourth edition appeared in 2013 (an Arabic edition was published in 2001). With great diligence, he laid the groundwork for the second English-language edition during the past year-it turned out to be his last work.

The undersigned who knew Hans Gerd for many years was impressed not only by his knowledge and skills but also by his pleasant personality and his courage during the difficult period of his last years. He will be missed by his friends and colleagues.

Hans Gerd Schiefer is survived by his wife, Gunhild, and four children.

Alexander von Graevenitz

A. von Graevenitz $(\square)$

8802 Kilchberg, Zurich, Switzerland

e-mail: avg@imm.uzh.ch 